\title{
Making Outer Space Intimate: Familiar Scales and Strange Sites
}

\section{Please cite as:}

Oman-Reagan, Michael P. and Kira Turner. 2015. Making Outer Space Intimate: Familiar Scales and Strange Sites. Paper session reviewed by General Anthropology Division. 114th Annual Meeting of the American Anthropological Association; Denver, Colorado. 18-22 November.

Session Abstract: As scientific and technological engagements extend human activity to the edges of the solar system and beyond, we increasingly confront the familiar and the strange through both material and abstract encounters with outer space. The intimacy of these engagements becomes visible through ethnographic work on the practices, discourses, representations, materializations, and imagined worlds of outer space. Scientists, corporations, states, and others working in the contested terrains of space science and exploration are building diverse, often conflicting, visions for human futures in space. Narratives of space dominance, alongside venture capitalism and the space industry, explicitly aim for the privatization and commodification of other worlds, framing outer space as a resource-rich frontier to be settled in a new era of colonization.

In contrast to this trajectory of resource extraction and megaprojects for space settlement, this panel explores the potentialities and constraints of engaging with space science and technology through intimate scales of analysis. The oscillating boundaries where everyday experiences on Earth meet outer space projects disrupt the familiar/strange binary. The familiar ground beneath our feet suddenly seems strange when seen through a satellite's eye view, while the formerly strange landscapes of other worlds become familiar through the eyes of robots, telescopes, and spacecraft. Imagined travel into space and across interstellar distance transcribes human scale into vast cosmic dimensions, while images of galaxies and stellar phenomena work alongside otherworldly simulations to bring outer spaces into contact with earthly environments.

Building on anthropology's attunement to multiple registers of inquiry, this panel finds intimate engagements with outer space in studies of: the imaginaries of astronomical image making; the politics of otherworldly analog and simulation science; views from the ground and views from space in climate science; the inscription of interstellar space as a site of travel, communication, and speculation; indigenous people's cosmologies, spaceport construction, and space tourism; and ontologies of space debris in locales both proximate and remote to spacecraft launch sites. These intimate encounters with space shift the cosmos from something remote 'out there' into a familiar locale with attendant earthly consequences from awe and hope to conflict and danger. At stake is an understanding of how our activity in space increasingly shapes the ways we imagine and plan for human futures both on and off planet Earth.

\section{Participants and Papers:}

\section{Metering from the Ground, Monitoring from Space: The Politics of Scale in California's "Hidden Drought"}

Emily Brooks (University of California, Irvine)

Unfolding the Space Between Stars: Anthropology of the Interstellar

Michael P. Oman-Reagan (Memorial University of Newfoundland) 
Spectrum of the Visible: An Exploration of Astronomical Image/Inaries

Rosalie Allain (University College London)

Debris: Towards Symmetrical Anthropology of Space Industry's Externalities

Ludek Broz (Academy of Sciences of the Czech Republic)

Meeting the Northern Lights. Space Tourism in Sapmi, Sweden: Methodological and Ethical Issues

Consuelo Griggio (Memorial University of Newfoundland)

What's in the Mars Jar? Cold War Astrobiology and the Idea of Mars As a Microbial Place

Jordan Bimm (HSS/NASA/York University)

Discussant

Lisa Messeri (University of Virginia)

\section{Details:}

Time: Saturday, November 21, 2015: 8:00 AM-9:45 AM

Conference: $114^{\text {th }}$ American Anthropological Association Meeting November 18-22, 2015

Location: Colorado Convention Center, Denver, Colorado, USA

Reviewed By: General Anthropology Division

Organizers and Chairs: Michael P. Oman-Reagan (Memorial University of Newfoundland) and Kira Turner (York University)

Discussants: Lisa Messeri (University of Virginia)

\section{Contact:}

Michael P. Oman-Reagan: omanreagan@mun.ca

Kira Turner: k4turner@yorku.ca 